\title{
HISTORIA DE UN MOVIMIENTO: EL 15-M COMO EXPRESIÓN DEL MALESTAR SOCIAL
}

\author{
Aleix Romero Peña* \\ Universidad de La Rioja
}

http://dx.doi.org/10.5209/rev_NOMA.2015.v46.n2.51418

Resumen.- No cabe duda que el 15-M ha venido marcando los acontecimientos políticos y sociales en España desde su eclosión en 2011. Sin embargo, este movimiento, por su cercanía temporal, aún no ha sido estudiado en profundidad. En las siguientes páginas planteamos una aproximación siguiendo un método histórico.

Palabras clave.- 15-M, movimiento social, asamblea, sociedad civil, elecciones.

\section{History of a movement: the 15-M as expression of social discomfort}

\begin{abstract}
It's evident that the 15-M movement has marked political and social events happened in Spain since its emergence at 2011. However, this movement, for its temporary proximity, hasn't been still studied profoundly. We consider a nearness at the following pages according to a historical method.
\end{abstract}

Keywords.- 15-M, social movement, assembly, civil society, elections

\section{Introducción. Un día, un movimiento}

El 15 de mayo de 2011 fue el momento inaugural de un ciclo de protestas populares que toma a las medidas de austeridad económica y al inmovilismo político como sus principales bestias negras. En aquellos compases el movimiento 15-M recibió gran parte de su relevancia gracias a una aburrida y previsible campaña -la de las elecciones autonómicas y locales del 22 de mayo- que terminaría convirtiéndose en un magnífico trampolín de salida ${ }^{1}$.Los acontecimientos en principio localizados en un área del centro de Madrid, ampliamente difundidos por los medios de comunicación y las redes sociales, traspasaron su ámbito inicial de repercusión.

El 15-M recoge una serie de inquietudes sociales para las que las élites políticas no tenían respuesta. Precisamente uno de los logros indiscutibles de este movimiento fue implicar en él a varios miles de personas al margen de la

\footnotetext{
* Doctor en Ciencias Humanas por la Universidad de La Rioja, colabora con el Grupo de Investigación de Historia de Nuestro tiempo de dicho centro y es investigador agregado del Instituto de Estudios Riojanos.

Quiero agradecer a Carlos Navajas, Jakue Pascual, Guiomar Castaños y Ana sus consejos e indicaciones, sin los cuales hubiera sido imposible abordar las siguientes páginas.

${ }^{1}$ (2011) TAIBO, Carlos, Nada será como antes: sobre el movimiento 15-M, Ed. Los Libros de la Catarata, Madrid, pp. 25-26.
} 
maquinaria de los partidos y de otras organizaciones tradicionales. Eslóganes como "lo llaman democracia y no lo es", "no hay pan para tanto chorizo", "somos el 99 \%" o "no nos representan", anticipaban un nuevo discurso en el que el centro de gravedad se sitúa en una población que se siente desarraigada con respecto a sus representantes políticos. El 15-M se convirtió además en un referente movilizador para todos aquellos que deseaban canalizar su malestar social y personal organizando la desobediencia, como decía el sociólogo Jakue Pascual en Gara $^{2}$, en la idea de que sus derechos fundamentales estaban siendo infringidos.

El 15-M se identifica a sí mismo como un grupo transversal e intergeneracional de personas, que se reúnen en espacios públicos y abiertos para tratar sobre distintas cuestiones que les afectan en su vida cotidiana, articulándose en asambleas soberanas donde se toman las decisiones mediante un proceso deliberativo. Merece la pena subrayar, aunque sea de pasada, la trascendencia que podría haber tenido este modelo organizativo para la pedagogía de una sociedad civil tradicionalmente débil. Así aparecen encuestas que reflejan la importancia del 15-M como experiencia de participación política ${ }^{3}$

Las asambleas suponen el aprendizaje de una democracia efectiva y real, que va más allá de los ropajes formales con que se revisten los regímenes vigentes. Pero no sólo es importante la toma de decisiones, sino también su ejecución, y es precisamente de ahí de donde parten algunas de las críticas más destacadas. Según Luis Bouza, el 15-M consiguió cambiar las reglas de juego -erosionando el apoyo a los dos grandes partidos, introduciendo nuevos temas en la agenda política o normalizando nuevas formas de realizar demandas-, pero no pudo revolucionar el sistema político ${ }^{4}$. En este sentido, puede plantearse qué ha conseguido el 15-M en cuanto a las reivindicaciones planteadas y los resultados conseguidos. Afrontaremos esta tarea mediante un ejercicio histórico donde la cronología adquirirá un papel relevante, centrándonos en la primera fase del movimiento, la que abarca el periodo acotado entre el 15 de mayo y el 20 de noviembre de 2011, el momento en que la influencia política lograda en un primer momento -cuantificable a través de los resultados de los comicios del 22 de mayo- no se vio validada en las elecciones generales ${ }^{5}$.

\section{El contexto. Choque cultural}

La irrupción del 15-M impulsó una corriente de reflexión sobre el origen y las causas de la crisis financiera que fue más allá del simple eslogan Esto lo arreglamos entre todos, el nombre que recibió en 2010 una campaña

\footnotetext{
2 "Desobediencia", Gara, 12/5/2011.

${ }^{3}$ Según la "Encuesta $15-M$ ", en la que participaron unas 4.304 personas, para la mitad este movimiento constituyó su primera experiencia política. eldiario.es, 15/5/2013. $<$ http://www.eldiario.es/sociedad/encuesta-activista-simpatizante-militantepolitica_0_132636907.html>

4 "¿Es el 15-M antipolítico? Marcos de protesta y agenda política". eldiario.es, 16/3/2013. $<$ http://www.eldiario.es/agendapublica/blog/antipolitico-Marcos-protesta-agendapolitica_6_111348865.html>

(2011) ERREJÓN, Íñigo, "El 15-M como discurso contrahegemónico", Encrucijadas. Revista de Ciencias Sociales, $\mathrm{n}^{\circ}$ 2, pp. 120-145.
} 
institucional para estimular la economía ${ }^{6}$. Este fenómeno posibilitó la discusión del paradigma cultural hegemónico, caracterizado por el consenso entre las masas y las élites dirigentes, donde los intelectuales han tenido un relevante papel como representantes del aparato ideológico, según la concepción gramsciana ${ }^{7}$. No es punto baladí el de resaltar esta última circunstancia. En la España de la transición las filas de la izquierda -especialmente en el PCE y el PSOE- contaron con la presencia de intelectuales muy influidos por la lectura de Gramsci. Conforme la democracia iba consolidándose, muchos de ellos fueron olvidando paulatinamente su compromiso con la lucha de clases, pero sin perder su condición autorreferencial de intelectual colectivo: ahora bien, en vez de identificarlo con un partido, según postulaba Gramsci, pasaron a hacerlo con los conglomerados mediáticos ${ }^{8}$.

A raíz del 15-M este consenso fue identificado como Cultura de la Transición, un concepto realmente difícil de caracterizar. De acuerdo con uno de sus principales impulsores, el periodista Guillem Martínez, se refiere a la cultura española surgida con posterioridad a 1976 que presenta las siguientes características: no construir objetos problemáticos y ubicarse en una posición acomodaticia con los poderes político y económico ${ }^{9}$. Se insiste en el hecho de que el 15-M ha conseguido "emborronar" la Cultura de la Transición ${ }^{10}$, pero hay que destacar también sus límites. Desde 2011 varios de los intelectuales que podrían ser inscritos en la nómina de la Cultura de la Transición han seguido transmitiendo los mismos mensajes. En el ensayo Todo lo que era sólido, que fue publicado en 2013, se pasaba revista a los desmanes políticos, económicos y morales de los últimos años. La conclusión de su autor, el reconocido escritor Antonio Muñoz Molina, resultaría desconcertante para cualquiera interesado en la asunción de responsabilidades políticas. Según él, desde que comenzara a afluir dinero al país después de la entrada en la Comunidad Europea, pero especialmente tras la adopción de una moneda única y la generalización del crédito barato, la población había vivido inmersa en una especie fantasía colectiva y alienante: "cuanto más dinero había los simulacros se fueron haciendo más perfectos, y ni quienes los organizaban ni quienes informaban sobre ellos ni la ciudadanía que los admiraba eran capaces ya de distinguir la

\footnotetext{
${ }^{6}$ El economista Guillermo de la Dehesa hizo en la presentación de aquella campaña "una llamada a la sociedad civil para salir de la crisis" y pidió "que prime el consenso frente a las ideologías (sic)". El País, 26/10/2010. Casi inmediatamente surgieron grupos y páginas en las redes sociales en clave irónica, como Esto lo arreglamos sin ellos.

${ }^{7}$ (2006) BOBBIO, Norberto, Estado, gobierno y sociedad. Por una teoría general de la política, ed. Fondo de Cultura Económica, México D. F., pp. 48-49.

${ }^{8}$ Sobre la presencia de Gramsci en la transición española, (1998) OÑATE, Pablo, Consenso e ideología en la transición política española, Centro de Estudios Políticos y Constitucionales, Madrid, pp. 122-123 y n. 64; (2014) QUAGGIO, Giulia, La cultura en transición, Ed. Alianza Editorial, Madrid, p. 268. Sobre la evolución de estos intelectuales a la derecha, (2007) MUÑOZ SORO, Javier, "Sin complejos: las nuevas derechas políticas españolas", Historia y política, $\mathrm{n}^{\circ}$ 18, pp. 129-164.

9 "¿La Cultura de la Transición se muere?”. El País, 11/06/2011. Para conferirle seriedad, se nos dice que se fundamenta en la antropología cultural, las teorías de la recepción, la teoría de los marcos y los culture studies, así como el periodismo. (2012) MARTíNEZ, Guillem, "El concepto CT", en MARTíNEZ, Guillem. CT o la Cultura de la Transición. Crítica a 35 años de cultura española, Ed. Debolsillo, Barcelona, pp. 13-14.

${ }^{10}$ (2012) FERNÁNDEZ-SAVATER, Amador, "Emborronar la CT (del "No a la guerra" al 15-M)", en ibídem, pp. 37-52.
} 
realidad de la representación"11. La moraleja nos retrotrae de nuevo al mensaje de Esto lo arreglamos entre todos: como la culpa es colectiva, tampoco resulta tan chocante que la responsabilidad quede en manos de quienes anteriormente nos habían conducido al desastre.

El cuestionamiento cultural surge por tanto desde abajo y forma parte del fenómeno que Fernando Vallespín diagnosticó como "fatiga democrática", común a los países miembros de la Unión Europea y que está caracterizado por el divorcio entre la población y la oligarquía dominante, con el consiguiente descrédito de la democracia liberal ${ }^{12}$. Este malestar ciudadano puede ser rastreado con anterioridad al 15 de mayo de 2011. Desde comienzos de la década del 2000 la movilización social ha aumentado y se ha normalizado, especialmente en la modalidad de las manifestaciones. Se ha interpretado este incremento como el producto de un sentimiento de desafección al alza, que proviene de diferentes ámbitos del espectro político, tanto a la izquierda como a la derecha ${ }^{13}$. Un descontento que descansaba en la profunda desigualdad existente años antes de la crisis, que dividía a España en dos según Vicenç Navarro. La primera, conformada por el 30-35 \% de la población, disponía de rentas superiores y tenía influencia decisiva en la cultura política y mediática, componiéndose principalmente por las clases medias de renta alta. A diferencia de esta, la segunda, que suponía el 60-65\%, aglutinaba a las clases trabajadoras y clases medias de renta baja, caracterizándose especialmente por ser la usuaria de los servicios públicos ${ }^{14}$. Otros expertos venían denunciando la crisis del Estado del Bienestar, silenciamiento de voces críticas como aquellas que denunciaban antes de la crisis la entrada del Estado del Bienestar ante el vertiginoso proceso de asistencialización, advirtiendo que terminaría generando una dualidad en función de la inserción en el mercado de trabajo entre integrados y no integrados o precarizados ${ }^{15}$.

Se trata, en definitiva, del fortalecimiento de una sociedad civil que los desajustes de la transición habían debilitado. Realizando un ejercicio de comparación entre los casos portugués y español, Robert Fishman comprobó que en el país luso -cuya democratización vino al socaire de una revoluciónesta presenta mayor fortaleza, constatable en superiores niveles de educación cívica, la trascendencia del debate público, la gestión de la administración pública o la actitud de los políticos hacia las reclamaciones populares ${ }^{16}$. La primera en ser cuestionada fue la versión oficial de la transición política, que puede ser resumida grosso modo como el eclipse del protagonismo de las

${ }^{11}$ (2013) MUÑOZ MOLINA, Antonio, Todo lo que era sólido, Ed. Seix Barral, Barcelona, pp. 106-107.

${ }^{12}$ (2011) VALLESPÍN, Fernando, "La fatiga democrática", Claves de razón práctica, nº 215, pp. 10-18.

${ }^{13}$ (2011) JIMÉNEZ SÁNCHEZ, Manuel, La normalización de la protesta. El caso de las manifestaciones en España (1980-2008), Centro de Investigaciones Sociológicas, Madrid.

${ }^{14}$ (2006) NAVARRO, Vicenç, El subdesarrollo social de España: causas y consecuencias, Ed. Anagrama, Barcelona, pp. 30-32.

15 (2000) NOGUERA, José Antonio, "La restauración de la política social en España: conclusiones", en ADELANTADO, José (coord.), Cambios en el Estado del Bienestar: políticas sociales y desigualdades en España, Ed. Icaria, Barcelona, pp. 475-502.

${ }^{16}$ (2004) FISHMAN, Robert, "Legacies of democratizing reform and revolution: Portugal and Spain compared". Paper presentado en un seminario del Instituto de Ciências Sociais de la Universidade de Lisboa, 27/4/2004. Posteriormente, Fishman ha desarrollado su perspectiva en otros trabajos. 
fuerzas sociales para poner el foco en las actitudes y comportamientos de los miembros de una minoría, que en ciertos casos sólo contaron con el respaldo representado por sus propias personas ${ }^{17}$. La lectura negativa del periodo era anterior, pero fue a partir del 15-M cuando comenzó a traspasar determinados ambientes políticos y académicos. Se comienza a difundir una interpretación que ve la transición como una operación diseñada por las élites franquistas para facilitarse un fácil y cómodo aterrizaje en un nuevo contexto que reproduciría bastantes aspectos del anterior. Implícitamente, se censura la actuación de los dirigentes de las principales organizaciones antifranquistas.

Aunque se insiste en que este juicio no tiene una base historiográfica seria ${ }^{18}$, conviene subrayar que no se trata tanto de la condena de unos hechos pasados, como del reconocimiento de la sombra que cubre a las decisiones y pactos tomados en aquel tiempo que, constreñidos por unas circunstancias complejas y castradoras, se extiende hasta la actualidad. La transición se convierte en un relato que legitima la situación política vigente en su sentido más inmovilista; de ahí que la sociedad civil reevalúe el legado de aquel tiempo entendiendo que hay una continuidad entre la dictadura y la democracia que posibilitó la supervivencia de antiguos ministros, funcionarios e instituciones ${ }^{19}$. Es consciente, además, de que existe un pacto de silencio sobre los aspectos más traumáticos del pasado: no hablamos aquí de la cultura, donde tuvo lugar una auténtica "saturación de la memoria"20, sino de la política y de la judicatura ${ }^{21}$. La polémica abierta por la vigencia de la Ley de Amnistía de 1977 y la imposibilidad consiguiente de investigar diversos crímenes por las autoridades franquistas es muy ilustrativa al respecto.

Durante estos años el auténtico pilar del paradigma cultural dominante ha sido el consenso entre los dos grandes partidos ${ }^{22}$ gracias al modelo constitucional español, que sienta las bases del "bipartidismo imperfecto" ${ }^{23}$ que rige la política. La tónica de los acuerdos pasó por una etapa de turbulencias a partir del 11 de marzo de 2004, es decir, el día en el que se produjeron los atentados más cruentos y crueles de la historia reciente española. En el imaginario colectivo quedó marcada a fuego la relación entre este suceso y la decisión del Gobierno conservador de José María Aznar de embarcar a España en una guerra remota, la de Iraq, fundándose en argumentos discutibles que después demostrarían ser completamente falsos. La visionaria actuación del Ejecutivo de Aznar acabó volviéndose en su contra, especialmente después de saberse que había ocultado los avances de la investigación policial. La movilización social despertada, que en el fondo era el colofón de un ciclo de protestas que

\footnotetext{
${ }^{17}$ De cara a su impacto en la sociedad pública, merecen destacarse los agudos comentarios vertidos por José Andrés Rojo en su reseña al libro de Ferrán Gallego El mito de la transición. La crisis del franquismo y los orígenes de la democracia (2008). El País, 25/10/2008.

${ }^{18}$ (2005) YSÀS, Pere, "Una nota sobre la crisi del franquisme i la transició a la democracia", Revista HMiC: història moderna i contemporània, $\mathrm{n}^{\circ}$ 3, pp. 101-109.

${ }^{19}$ (2012) CAMPADABAL, Pep, "CT y política: la lucha por el punto medio. Del "pacto con el régimen, de entrada, no" a la victoria de la CT", en MARTíNEZ, G., CT ..., op. cit., pp. 71-73.

${ }^{20}$ (2013) QUAGGIO, G., La cultura..., op. cit., pp. 199-264.

${ }^{21}$ (2014) CLAVERO, Bartolomé, España, 1978: la amnesia constituyente, Ed. Marcial Pons, Madrid.

22 (2012) ORTIZ HERAS, Manuel, "Nuevos y viejos discursos de la Transición: la nostalgia del consenso", Historia Contemporánea, $\mathrm{n}^{\circ}$ 44, pp. 337-367.

${ }_{23}$ (2009) FERNÁNDEZ SARASOLA, Ignacio, Los partidos políticos en el pensamiento español. De la llustración a nuestros días, Ed. Marcial Pons, Madrid, pp. 322-323 y 335-337.
} 
habían comenzado dos años antes denunciando las políticas del PP y reclamando una regeneración de la vida política española ${ }^{24}$, logró que en las elecciones generales del 2004 el PSOE obtuviera la victoria a través de un porcentaje considerable de votos provenientes de la abstención ${ }^{25}$.

Con anterioridad a aquel 11 de marzo, la meta de los principales medios de comunicación, más allá de la adscripción política que los consumidores otorguen a cada uno, era apuntalar la política gubernamental mediante una estrategia de legitimación/deslegitimación de las protestas sociales ${ }^{26}$. Esta práctica sufrió un pequeño pero significativo desgarro en las jornadas posteriores al 11-M, cuando se escenificó una división entre aquellos que apoyaron la tesis gubernamental de que los atentados los había cometido ETA, y los que por el contrario le acusaron de estar ocultando datos. Si bien la respuesta social cogió a todos por sorpresa, viéndose forzados a emitir condenas o cuando menos desligarse públicamente de las concentraciones espontáneas frente a las sedes del $\mathrm{PP}^{27}$, el daño ya estaba hecho. La fabricación y difusión de la teoría conspirativa que se desarrolló como contrapartida a las críticas significó un punto de no retorno. El triunfo electoral socialista alentó la polarización política que llevó a ciertos sectores intelectuales a alertar sobre la posición pseudocrática del nuevo Ejecutivo de Zapatero $^{28}$, señalando que los atentados habían formado parte de un plan previamente orquestado para que el PSOE tomara el poder.

La victoria de José Luis Rodríguez Zapatero fue para las teorías de la conspiración un golpe de estado encubierto, tal y como denunciaron algunos colaboradores de la fundación FAES, del entorno del Partido Popular. Dando así por sentada la ilegitimidad en origen del nuevo Gobierno, estos mismos círculos denunciaron que algunas de las medidas aprobadas por Zapatero, presentadas como progresistas, encubrían un oscuro y nunca explicitado proyecto de "democracia radical"29, que tenía como principales ejes la negociación con ETA, la reforma de los estatutos de autonomía, la recuperación de la memoria histórica o ciertas medidas de contenido social,

\footnotetext{
${ }^{24}$ (2005) CARBó, Rosa, PRADEL, Marc, DUARTE, María Luisa y HERREROS, Tomás, "La última oleada de movilizaciones (2002-2004)", en IBARRA, Pedro y GRAU, Elena (coords.), La política en la red: anuario de movimientos sociales, Ed. Icaria, Barcelona, pp. 35-52.

${ }^{25}$ (2009) GONZÁLEZ, Juan Jesús y BOUZA, Fermín: Las razones del voto en la España democrática, 1977-2008, Ed. Los Libros de la Catarata, Madrid, pp. 152-153.

${ }^{26}$ Como se puede comprobar en la cobertura del desastre ecológico del Prestige, cuando, según un estudio, los periódicos de mayor tirada otorgaron el protagonismo como interlocutor principal al Gobierno central, seguido por la Xunta de Galicia y el PP, en una jerarquía institucional donde el último lugar estaba ocupado por la plataforma reivindicativa Nunca Máis, a pesar de llevar a cabo importantes movilizaciones de denuncia. (2006) SAMPEDRO, Víctor y LÓPEZ-REY, José Antonio, "Nunca máis y la cara oculta de la esfera pública: control de la visibilidad mediática de un movimiento social", en NOS, Eloísa y GÁMEZ, María José (eds.), Medios de comunicación y solidaridad: reflexiones en torno a la (des)articulación social, Universitat Jaume I, Castellón, pp. 88-103.

${ }^{27}$ En su editorial "Más que nunca: a las urnas, ciudadanos", El País, periódico señalado por el Gobierno de alentar y difundir las concentraciones, acusaba a algunos manifestantes de conducirse "irresponsable e indebidamente" y animaba a sus lectores a votar para reforzar las instituciones. El País, 14/3/2004.

${ }^{28}$ (2009) SAMPEDRO, Víctor, "Conspiración y pseudocracia. O la esfera pública a cinco años del colapso del 11-M", Viento sur. Por una izquierda alternativa, no 103, pp. 60-68.

${ }_{29}$ (2005) SARASQUETA, Antxon, "EI proyecto de la izquierda española", Cuadernos de pensamiento político, $\mathrm{n}^{\circ}$ 5, pp. 147-166.
} 
donde se situarían la reforma de la ley del aborto o el reconocimiento del matrimonio entre personas del mismo sexo. Las dos legislaturas de Zapatero se caracterizaron por el ambiente de crispación entre los principales partidos del régimen, si bien los pilares del consenso preexistentes permanecieron intocables -lo que nos permite afirmar, citando a Guy Debord, que edificaron su unidad en el desgarramiento ${ }^{30}$. El espectáculo sirvió, no obstante, para desconcertar a la opinión pública, que empezó a incorporar algunas críticas de calado en el debate político, entendiendo que el régimen resultaba insuficiente para satisfacer las demandas de la ciudadanía.

Por más que el 15-M haya emborronado el paradigma cultural dominante, cabe poner algunas afirmaciones ${ }^{31}$ que dicen eufóricamente que las acampadas alentaran un discurso contrahegemónico. Sobre ese punto trataremos en los siguientes apartados.

\section{Del 15-M al 20-N: cronología y cuestiones básicas}

El 15-M se inscribe dentro de una dinámica de movilización social donde también habría que incluir la oposición a la entrada en la OTAN, la insumisión, la demanda del $0,7 \%$, la abolición de la deuda externa, el no a la guerra, las protestas de Nunca mais, etc. Son movimientos de acción colectiva que pretenden una implicación política por vías no institucionales, constituyendo un fenómeno corriente en las democracias liberales ${ }^{32}$. Uno de los aspectos que distingue al 15-M del resto es la trascendencia que adquieren las redes sociales cibernéticas como espacios para la expresión y toma de conciencia ciudadanas $^{33}$. Internet fue una herramienta fundamental, especialmente en los hitos previos al 15 de mayo, como la aparición de una plataforma virtual llamada Democracia Real Ya para el mes de marzo que disponía de una web y cuentas en Facebook y Twitter.

En principio Democracia Real Ya estaba llamada a ser un nombre más de los que componen la abultada lista del encapsulado mundo ciberactivista ${ }^{34}$, pero su vocación estaba en la calle. Compuesta principalmente por jóvenes estudiantes y trabajadores, Democracia Real Ya participó en una manifestación convocada en Madrid el 7 de abril por el colectivo universitario Juventud Sin Futuro para oponerse a los recortes sociales y educativos. El evento, difundido principalmente a través de las redes sociales, fue un éxito multitudinario en el que participaron más de dos mil personas de todas las edades, si bien quedó parcialmente ensombrecido por los disturbios y la detención de doce

\footnotetext{
${ }^{30}$ (1995) DEBORD, Guy, La sociedad del espectáculo, Ediciones Naufragio, Santiago de Chile, p. 31.

31 (2011) ERREJÓN, Í.: "El 15-M...", art. cit. , pp. 120-145.

32 (2007) KAASE, Max, "Perspectives on political participation", en DALTON, Russell J. y KLINGEMANN, Hans-Dieter (eds.), The Oxford Handbook of political behavior, Oxford University Press, Oxford-Nueva York, pp. 788-793.

${ }^{33}$ (2012) PEÑA ACUÑA, Beatriz, "Algunas perspectivas socioculturales de las redes sociales", en DE HARO, María Verónica, GRANDÍO, María del Mar y HERNÁNDEZ, Manuel, Historias en red: impacto de las redes sociales en los procesos de comunicación, Universidad de Murcia, Murcia, p. 319.

${ }^{34}$ (2011) SAMPEDRO, Víctor y SÁNCHEZ DUARTE, José Manuel, "Del 13-M al 15-M", Razón y fe: revista hispanoamericana de cultura, no 1353-1354, t. 264, pp. 99-105.
} 
manifestantes ${ }^{35}$. Con posterioridad, Democracia Real Ya anunció la realización para el 15 de mayo de varias manifestaciones en distintos puntos del Estado, contando con la adhesión de más de quinientas asociaciones, ninguna de ellas partido político ni sindicato. En la organización había alrededor de medio centenar de personas que coordinaban las manifestaciones previstas mediante asambleas realizadas en el centro social madrileño Patio de las Maravillas ${ }^{36}$. Miles de personas salieron el día señalado en al menos cincuenta ciudades españoles, marchando con el lema "No somos mercancía en manos de políticos y banqueros".

Tras la manifestación de Madrid, unas cuarentas personas decidieron de manera espontánea acampar en la Puerta de Sol, con el argumento de que la manifestación debía desembocar en algo más permanente, prolongándose por lo menos hasta las elecciones autonómicas y locales que iban a celebrarse el próximo 22 de mayo. Es el nacimiento oficial del 15-M, desde un principio claramente desvinculado de Democracia Real $\mathrm{Ya}^{37}$. Cuando dos días más tarde la policía desalojó Sol, ya había unos dos centenares de acampados, que se convertirían en miles tras la reocupación de la plaza esa misma tarde. Paralelamente, distintas ciudades se unían a las protestas plantando tiendas en espacios públicos. Para el 20 de mayo algunos cálculos estimaban que en España había ya unas sesenta acampadas y en el extranjero otras quince ${ }^{38}$.

Los medios de comunicación identificaron estas protestas con otro acontecimiento internacional que se estaba desarrollando de manera paralela, la famosa Primavera Árabe, cuyo nombre guarda el recuerdo de la famosa Primavera de los Pueblos que sacudió Europa en 1848. Desde los meses de otoño de 2010 el mundo árabe fue viviendo diferentes convulsiones que fructificaron ese mes de diciembre en la revolución tunecina, después de que un joven desempleado se quemara a lo bonzo. La inestabilidad contagió a Egipto en enero y destacó por los enfrentamientos entre partidarios y detractores del presidente Mubarak. Periódicos como El País no dudaron en confirmar que la Primavera Árabe también había llegado a España, equiparando a la Puerta del Sol, epicentro del 15-M, con la de Tahrir, su homóloga egipcia en la Primavera Árabe ${ }^{39}$. Pero, a diferencia de las revueltas árabes, la movilización española, por más que identificara como causantes del malestar al bipartidismo del PP el PSOE -junto con la corrupción, la banca o los grandes empresarios ${ }^{40}-$, no alimentaba una estrategia rupturista. Lo cual no fue óbice para que su protesta, especialmente en lo que respecta al mantenimiento de las acampadas, se viera como un desafío al orden. Un alarmado editorial de El País proclamó aquellos días su temor que de ellas saliera "una enmienda política a la totalidad sin que se identifique claramente la

\footnotetext{
35 "La manifestación de Juventud Sin Futuro acaba en bronca". El País, 7/4/2011.

36 "Así nació el 15-M". ABC, 22/5/2011.

37 "Los primeros cuarenta de Sol". Periodismohumano, 26/5/2011. $<$ http://periodismohumano.com/temas-destacados/los-primeros-40-de-sol.html>

38 "El espíritu de la acampada de Sol se reproduce por las ciudades españolas". El País, 20/5/2011.

${ }^{39}$ (2012) MARCO de PABLO, Laia, "Sobre las dificultades para la eficacia comunicativa de los Movimientos Sociales. Repensar y actuar", Fòrum de recerca, nº 17, p. 102.

40 "Los indignados salen a la calle". El País, 16/5/2011.
} 
alternativa, a no ser la evocación nostálgica de utopías que concluyeron en tragedia"41.

Una rápida mirada a los perfiles de quienes integraron el 15-M hubiese disipado cualquier asomo de sospecha. Los acampados eran personas de diferentes edades y condiciones que compartían una preocupación por los problemas actuales y la aspiración a promover una democracia más participativa y directa, aunque sin mayores concreciones ${ }^{42}$. Se pueden distinguir dos estratos sociales: las nuevas clases medias relacionadas con un sector servicios cada vez más empobrecido y los grupos desmercantilizados, como los parados, los estudiantes, las amas de casa, los jubilados, etc. ${ }^{43}$, unidos por su vulnerabilidad ante la crisis económica y su imposibilidad de acudir a vías clásicas de movilización, como las huelgas. No demostraron ninguna inclinación a la utopía, ni mucho menos a la tragedia. Las 16 propuestas acordadas el 20 de mayo por Acampada Sol ratificaron los planteamientos posibilistas del movimiento: cambios en la ley electoral para que las listas fuesen abiertas y con circunscripción única; cumplimiento de algunos derechos básicos reconocidos por la propia Constitución, como una vivienda digna, la libre circulación de personas o educación y sanidad públicas y de calidad; abolición de medidas impopulares como el Plan Bolonia, la Ley de Extranjería o la Ley Sinde contra las descargas en Internet; condena de la corrupción y exigencia de transparencia a instituciones y partidos; separación tanto entre Iglesia y Estado como entre los poderes ejecutivo, legislativo y judicial; recuperación de la Memoria Histórica; existencia de unos medios de comunicación éticos y veraces; etc. ${ }^{44}$ El discurso del 15-M se enmarca dentro del "nuevo paradigma político" descrito por Pablo Oñate, que, presentado de manera fragmentada, enfatiza su carácter pluralista, por lo que puede parecer demasiado generalista e incluso impreciso, dando la impresión de haber sido confeccionado de manera ad hoc y de pretender centrarse principalmente en una filosofía negativa ${ }^{45}$

El 15-M es un movimiento horizontal, asambleario, apartidista y sin líderes visibles, cuyo objetivo no era socavar el sistema, sino promover una serie de reformas. La conocida como indignación no alienta ningún conato de rebelión, sino que por el contrario es un instrumento de concienciación ${ }^{46}$ para difundir un mensaje de advertencia sobre la acentuación de la brecha social como consecuencia de la crisis económica, dirigiéndolo tanto a las masas como a las élites. Aunque se haya afirmado también que en el 15-M existen "dos almas", una libertaria y otra reformista ${ }^{47}$, se aprecia sin embargo que las tendencias de carácter más radical, combativo o anticapitalista acabaron siendo neutralizadas

\footnotetext{
41 “Indignados en la calle". El País, 17/5/2011.

42 (2013) PÉREZ VICENTE, Nuria, "El lenguaje político del 15-M: hacia una nueva retórica de la indignación", Signa: revista de la Asociación Española de Semiótica, nº 22, p. 570.

43 (2013) OÑATE, Pablo, "La movilización ciudadana en España en los albores del siglo XXI: una contextualización para el debate", Revista española de ciencia política, nº 33, p. 43.

44 Las propuestas de la Asamblea Sol están recogidas en: <http://wiki.15m.cc/wiki/Lista_de_propuestas_del_15M\#Consenso_Asamblea_Sol_20_de_may o de_2011>

${ }^{45}$ (2013) OÑATE, P., "La movilización...", art. cit., p. 42.

46 (2011) VALLESPÍN, F., "La fatiga...", art. cit., p. 18.

47 (2011) TAIBO, C., Nada será como antes..., op. cit., pp. 49-57.
} 
en su seno ${ }^{48}$. Llama también poderosamente la atención el enorme apoyo que concitó el movimiento entre la población española. Una encuesta realizada en días posteriores al 15 de mayo revela que una inmensa mayoría -el $81 \%$ - da la razón a los indignados, un porcentaje algo mayor -el $84 \%$ - considera que el 15-M trataba asuntos que afectan directamente a la ciudadanía y es casi unánime -un $90 \%$ - el cuestionamiento hacia los partidos y la demanda de que introdujeran cambios en su forma de actuar $^{49}$.

Semejante sostén catapultó al 15-M a un éxito de enormes proporciones, convirtiéndose para las instituciones en una amenaza de derivas incontrolables. El Ejecutivo de Zapatero, con una popularidad lastrada por la crisis económica y la mirada puesta en las dos citas electorales que se agolpaban el mismo año, respondió de manera titubeante. El 19 de mayo la Junta Electoral Central acordaba prohibir concentraciones y manifestaciones el día 21, la jornada de reflexión, pero miles de personas se saltaron el veto ocupando pacíficamente varias plazas españolas. El Ministerio del Interior determinó no ordenar un desalojo policial, despertando las quejas del $\mathrm{PP}^{50}$. Fue una gran victoria para el movimiento que, aunque forzado a no dar consignas de voto, consiguió tener un impacto considerable en las elecciones, no a través del respaldo a una candidatura, sino incrementando la proporción de votos nulos y en blanco, que terminaron convirtiéndose en la cuarta opción política -a excepción de la Comunidad Autónoma Vasca, donde la legalización de Bildu provocó un repunte de la participación electoral- ${ }^{51}$. Esto explica que los resultados electorales globales, que dieron la victoria al PP, no desalentaran a los acampados.

A partir de las elecciones el 15-M se consolidó, constituyendo varias comisiones y grupos de trabajo que tuvieron que bregar en medio de una complejidad creciente. En algunos momentos la intención de abarcarlo todo ocasionó graves obstáculos para el ejercicio interno de la democracia directa. La comisión de Acción en Sol coordinaba a siete grupos de trabajo Propuestas Ciudadanas, Educación y Cultura o Medio Ambiente-, que a su vez aglutinaban otros subgrupos. Medio Ambiente integraba por ejemplos soberanía alimentaria, gestión del territorio, residuos, medio rural y marino, educación, control industrial, dignidad animal, decrecimiento, energía y cambio climático, logística de la acampada y buzón de sugerencias, etc. ${ }^{52}$ Tales magnitudes impedían mantener siquiera una participación activa en la asamblea general, como se quejaba amargamente un militante anarquista que participaba en la acampada de Barcelona ${ }^{53}$. Por otro lado, pese al volumen creciente de temas a tratar, el principal punto de discusión en el que

48 (2012) COLECTIVO CUL DE SAC, 15-M. Obedecer bajo la forma de rebelión, Ediciones de El Salmón, pp. 21-23.

49 "La gran mayoría respalda la indignación del 15-M". El País, 5/6/2011.

50 "Interior descarta el desalojo de Sol". El País, 21/5/2011.

51 (2011) DIRECCIÓN GENERAL DE POLÍTICA INTERIOR, "El voto en blanco y el voto nulo en las elecciones locales del 22 de mayo de 2011", Seguridad y Ciudadanía. Revista del Ministerio del Interior, $\mathrm{n}^{\circ}$ 6, pp. 303-312.

52 (2011) BOTELLA-ORDINAS, Eva, "La democracia directa de la Puerta de Sol". La vie des idées. <http://www.booksandideas.net/La-democracia-directa-de-la-Puerta.html

${ }_{53}$ "Apagafuegos e incenciadores" Alasbarricadas Noticias, 6/10/2011 $<$ http://www.alasbarricadas.org/noticias/node/17885>. El artículo apareció originariamente en inglés como "Fire extinguishers and fire starters" en el portal Crimethlnc. 
coincidieron la mayoría de las acampadas fue el de la ocupación de las plazas, donde ya empezaron a vivirse varios problemas de convivencia interna. Pronto cobró fuerza la necesidad de un repliegue estratégico que pasara por la disolución de las acampadas y el traslado de la actividad a los barrios ${ }^{54}$, renunciando con ello a uno de los principales logros del movimiento: la recuperación civil del espacio público. La asamblea de Sol acordó el 11 de junio abandonar la plaza dejando un punto de información permanente y desvinculándose de los "irreductibles" que decidieron quedarse ${ }^{55}$.

También provocó una gran división el debate sobre la violencia, azuzado por los cada vez más frecuentes momentos de tensión entre los acampados y las fuerzas policiales. El 26 de mayo los Mossos d’Esquadra y la Guardia Urbana de Barcelona llevaban a cabo una operación conjunta para desalojar el campamento de la Plaza de Catalunya, que desembocó en cargas policiales que provocaron varios heridos ${ }^{56}$. El 15 de junio, durante una concentración en las inmediaciones del Parlament catalán para protestar contra la votación de graves recortes, hubo varios incidentes en los cuales los diputados fueron insultados, abucheados, zarandeados, escupidos y agredidos. Aunque la comisión de Comunicación de Asamblea Barcelona sacó un comunicado condenando todos los actos violentos, tanto los realizados por los antidisturbios como por los manifestantes, y asegurando que el grueso de la movilización se decantó por la "resistencia activa no violenta" ${ }^{57}$, no consiguió frenar la ofensiva contra su imagen. La prensa -aquellos medios que mostraron una visión condescendiente y paternalista hacia el movimiento ${ }^{58}$ - pasó de criticar su carácter asambleario, entendiendo que era incapaz de ofrecer soluciones a "complicados problemas de diseño", según señalaba el profesor universitario Félix Ovejero ${ }^{59}$, a la impugnación mediante exabruptos, como fue el caso del sociólogo conservador y futuro ministro de Educación José Ignacio Wert, que despachó en un artículo de opinión al 15-M como "populismo, demagogia y explotación de los sentimientos antipolíticos" $"$.

No obstante, puede concluirse que el problema más grave del movimiento fue su falta de concreción. Debido al afán de satisfacer a todo el mundo, el 15-M no encontraba una brújula que le permitiera para seguir su propio camino. Hubo un momento en que pareció representarlo la lucha contra el austericidio que imponía el Pacto del Euro, es decir, la hoja de ruta de la Unión Europea para hacer frente a la crisis económica. Para el 19 de junio se convocaron decenas de manifestaciones en las que el movimiento confluyó con los sindicatos para denunciar el ataque a la soberanía de los estados y los derechos de la ciudadanía" que básicamente implicaba la reducción de los salarios y del gasto

\footnotetext{
54 (2011) TAIBO, Carlos, El 15-M en sesenta preguntas, Ed. Los Libros de la Catarata, Madrid.

55 "Los irreductibles del 15-M". El Mundo, 12/6/2011.

${ }^{56}$ Hubo 84 manifestantes y 37 agentes heridos. Hasta un total de 180 personas presentaron, según Amnistía Internacional, denuncias por lesiones <http://www.amnesty.org/en/library/asset/EUR41/008/2011/en/731cdeda-2343-46a4-b5815f89c781793a/eur410082011es.pdf>

57 <http://acampadabcn.files.wordpress.com/2011/05/comunicado15j.pdf>

58 (2011) TAIBO, C., Nada será como antes..., op. cit., pp. 59-64. Los medios construyeron la imagen del 15-M. (2011) VALLESPÍN, F., "La fatiga democrática...", art. cit., p. 17.

59 "La ignorancia de los indignados". El País, 12/6/2011.

60 "Descifrando la indignación". El País, 30/6/2011.
} 
público $^{61}$. Más de dos centenares de miles de personas en unas sesenta ciudades apoyaron las movilizaciones en un ambiente calculadamente pacífico y festivo ${ }^{62}$. El 15-M no sólo consiguió en esta ocasión recomponer su imagen mediática, sino que también daría coherencia a sus reivindicaciones, centrándose en el objetivo de impedir una firma que implicaría la entronización de las políticas de austeridad. Pero, a diferencia de lo que plantean autores como Jesús Casquete ${ }^{63}$, hay que resaltar que no consiguió condicionar la agenda política.

El 20 de junio el Congreso de los Diputados aprobó de manera unánime una moción para "examinar las medidas que sean necesarias para profundizar en la democracia y la participación política, además de la transparencia y control de las instituciones democráticas". Más allá de las apariencias, era una declaración de intenciones en una moción no vinculante y de mínimos, que había sido acordada después de un encendido debate donde los partidos sólo conseguían entenderse a la hora de defender su actividad como representantes de la ciudadanía ${ }^{64}$. Quedaba claro que los temas políticos los marcaban los dictados de los organismos financieros internacionales, que la clase, casta o nomenclatura -denominación esta última acuñada por Francisco Vallespín ${ }^{65}$ - política, cuyo principal afán es retener sus privilegios. El 27 de junio, como era previsible, el Pacto del Euro fue ratificado en Bruselas por todos los estados miembros de la Unión Europea.

Las manifestaciones multitudinarias del 19 de junio fueron continuadas el mes siguiente por diferentes marchas indignadas que se echaron a las carreteras para ocupar Madrid el día 23, en un encuentro que reuniría otra vez a varios miles de personas. Por entonces el 15-M ya comenzaba a manifestar indicios de agotamiento, que se plasmaban en una escasez de ideas y en una corroborada incapacidad para plantear una alternativa a la respuesta institucional: se realizó una acampada en las inmediaciones del Congreso que intentó hacer llegar a los diputados un documento con varias reclamaciones que no serían atendidas ${ }^{66}$. El reflujo propio de la temporada estival propició que las asambleas perdieran afluencia, facilitando de paso la labor represiva. En agosto el papa Benedicto XVI pisó por primera vez Madrid con motivo de la celebración de la Jornada Mundial de la Juventud de 2011. Esta presencia serviría de excusa para poner coto a la presencia pública del 15-M. El 2 de agosto fue retirado el punto informativo del 15-M que quedaba en la Puerta de Sol. Durante tres días seguidos se intentó retomar el espacio, generándose una especie de estado de excepción en el centro de Madrid que acabó con varias cargas policiales, así como heridos y detenidos ${ }^{67}$. El 17 de agosto una

\footnotetext{
${ }^{61}<$ http://madrid.tomalaplaza.net/2011/06/18/razones-contra-el-pacto-del-euro/>

62 "El 19-J invade las calles de España". El País, 19/6/2011.

${ }^{63}$ (2011) CASQUETE, Jesús, "Balance preliminar de la indignación", El Viejo Topo, nº 286, pp. 19-25.

64 "El Congreso de los Diputados aprueba por unanimidad estudiar propuestas del 15-M". El País, 21/6/2011.

65 (2011) VALLESPÍN, F., "La fatiga...", art. cit., pp. 11-16

66 "Las propuestas indignadas entra en el Congreso". Público, 27/7/2011.

${ }^{67} \mathrm{La}$ Asociación de la Prensa de Madrid denunció que varios informadores fueron detenidos y agredidos mientras cubrían las protestas. $<$ http://www.apmadrid.es/noticias/generales/detenidos-y-golpeados-varios-periodistas-mientrascubrian-las-ultimas-protestas-del-15m?ltemid=209> El 5 de agosto unas cinco mil personas se manifestaron finalmente en Sol, pero no se quedaron a acampar.
} 
manifestación laica terminó también con choques con la policía ${ }^{68}$. El balance final fue que los peregrinos tomaron el relevo de los indignados en las calles madrileñas, gracias a la protección que disfrutaron los primeros y al hostigamiento que sufrieron los últimos.

Agosto fue también el mes en que tuvieron lugar también unos disturbios en Londres como consecuencia de la muerte de una persona a manos de la policía en un suburbio de la capital británica. El suceso pronto derivó en una oleada de saqueos e incidentes protagonizados por una población oprimida por el color de su piel y duramente castigada además por los recortes. Las comparaciones establecidas en España entre aquellos sucesos y el 15-M fueron rápidamente desechadas por los expertos, fundándose en la base social de este último movimiento, que "no es violenta"69. El descontento no provenía de la desesperación, como en Gran Bretaña; es más, el 15-M se presentaba a sí mismo como la encarnación del optimismo. Por eso, a diferencia de la indignación de los suburbios londinenses, el 15-M español tiene una más que evidente relación con movimientos como el norteamericano Occupy Wall Street, que desde el día 17 de septiembre enseñoreaba el parque Zuccotti en Manhattan, en pleno corazón neoyorkino.

Tras el verano los indignados se implicaron en el apoyo a otros movimientos como la Plataforma de Afectados por la Hipoteca (PAH), surgida con anterioridad al 15 de mayo. La lucha las hipotecas habían sido uno de los puntos recurrentes en las discusiones de las asambleas, que terminaron decantándose por apoyar sus actividades, que incluyen tanto tácticas de resistencia pasiva para frenar los desalojos como la ocupación de viviendas vacías de propiedad bancaria para reacomodar a los desahuciados. EI 15-M participó además en diferentes manifestaciones -desde el rechazo a la reforma exprés de la Constitución por incluir un mínimo de déficit tarifario a las reprobaciones públicas contra los recortes-, que le llevaron a confluir en las calles con sindicatos y partidos políticos, unas organizaciones que habían sido duramente cuestionadas en las acampadas. En este sentido destaca el apoyo de varias asambleas a la convocatoria de paro realizada por sindicatos minoritarios -Solidaridad Obrera, CNT, CGT, etc.- para el 29 de septiembre.

En octubre tuvo lugar el acto más destacado desde verano, la movilización mundial del día 15, que había sido preparada por Democracia Real Ya meses atrás y que se desarrolló en más de novecientas ciudades de unos ochenta y dos países ${ }^{70}$. Nuevamente los millares de personas que salieron a las calles reivindicando cambios y reformas se toparon con la incomprensión de la cale política, más preocupada por las elecciones generales que iban a celebrarse el 20 de noviembre que por las reclamaciones populares. Los comicios dieron la mayoría absoluta a un partido que iba a profundizar en la vía de recortes y contrarreformas y que representa los males denunciados por el movimiento: corrupción, opacidad, sordera ante las peticiones sociales, autoritarismo, etc. Cabe decir por tanto que el $20-\mathrm{N}$ fue el entierro de toda esperanza de regeneración política, obligando al 15-M a tener que decantarse por otra estrategia.

\footnotetext{
68 "La marcha laica". El País, 17/8/2011.

69 "Las revueltas callejeras: preguntas y respuestas". El Mundo, 10/8/2011.

70 "El movimiento de los indignados renace como una fuerza global". El País, 16/10/2011.
} 


\section{Un ejemplo de observación participante: el 15-M en Logroño}

El repaso cronológico del apartado anterior ha dejado algunas lagunas sobre el desarrollo interno del movimiento, que trataremos de rellenar con el ejercicio de observación participante que pudimos realizar en la asamblea de Logroño. Si bien es cierto que habría que estudiar si el caso es extrapolable a otro, contamos con la ventaja del grado de descentralización que experimentó el movimiento una vez difundido por todo el Estado. Pero antes es necesario tener en cuenta algunos datos socioeconómicos. A la altura de 2011 la comunidad autónoma de La Rioja podía afrontar la crisis con un moderado optimismo. Durante el primer trimestre anual la tasa de desempleo seguía siendo inferior a la media nacional, un 15,44 \%, pero los jóvenes eran la franja más afectada, con un porcentaje que se situaba en un preocupante $46,5 \%{ }^{71}$. Además, La Rioja era la quinta comunidad en cuanto a PIB per cápita. Se notó cierta recuperación económica con respecto al año anterior, con un incremento del $0,8 \%$, pero el tejido empresarial riojano es, pues se basa fundamentalmente en negocios de tamaño reducido: algo más de la mitad ni siquiera cuenta con asalariados ${ }^{72}$.

Los niveles de protesta social en La Rioja eran bajos. El 27 de enero tuvo lugar una manifestación convocada por la Red de Movimientos Sociales -compuesta por diferentes organizaciones y colectivos políticos, sindicales y sociales- para apoyar públicamente la convocatoria de una huelga general. Aunque la nutrida concurrencia -compuesta por dos centenares de personas- mostró el grado de malestar que existía en la sociedad riojana, la noticia apenas encontró hueco en los medios de comunicación regionales, ni tampoco se vio seguida por un calendario de acciones. Nada que ver por tanto con la situación de ciudades como Barcelona, donde con anterioridad al 15-M ya existían asambleas de barrio potentes y combativas ${ }^{73}$. Logroño se sumó al carro de las movilizaciones del 15 de mayo con una sentada pacífica en el paseo del Espolón. Entre el centenar de asistentes el periodista que cubrió el evento se fijó en la aparición de algunos nombres destacados de listas electorales que se presentaban a las elecciones que tendrían lugar siete días más tarde, como IU o Ecolo-Verdes de La Rioja ${ }^{74}$.

El 17, a través de invitaciones difundidas por las redes sociales, tuvo lugar en la Plaza del Mercado, en pleno casco antiguo logroñés, una reunión para decidir actos en solidaridad con los acampados de Sol, en la que se apostó instalar tiendas de campaña en aquel punto para el día siguiente ${ }^{75}$. Esta iniciativa partía, conviene ser subrayado, de un impulso minoritario -a la reunión asistieron unas treinta o cuarenta personas- y desconectado de la

\footnotetext{
${ }_{72}^{71} 20$ minutos, 24/7/2012.

<http://www.larioja.org/upload/documents/722117_indicadores_basicos_capitulo_01_indicadore S_economico.pdf>

${ }^{75}$ (2012) CASTAÑOS, Guiomar, "El 15-M en Barcelona", Ekintza Zuzena, no 39, p. 30.

74 "Alrededor de un centenar de "indignados"... de momento". La Rioja, 17/5/2011

75 (2011) CALVO, David y MORGA, Jairo: «El movimiento 15-M en Logroño. La democracia en la plaza», Piedra de rayo, nº 38, p. 39.
} 
sentada anterior. Algunos estudios ${ }^{76}$ distinguen la manifestación del 15 de mayo del movimiento $15-\mathrm{M}$, aduciendo que los participantes de una y otro presentan perfiles distintos y plantean metas diferentes. En el caso logroñés, por tanto, la sentada el día 15 consistió la adhesión a una campaña difundida a través de Internet, pero la decisión de plantar tiendas de campaña obedeció en cambio a un impulso solidario local y autónomo.

El 18 más de trescientas personas acudieron a una concentración convocada en la Plaza de Mercado que constituiría el prolegómeno a su ocupación. La portavoz de la asamblea organizadora -que se reivindicó, erróneamente, como Democracia Real Ya-, expresó "su enfado" por el hecho de que Logroño no hubiera seguido hasta ese momento el ejemplo de otras ciudades ${ }^{77}$, con lo que venía a decir que aquella era la fecha inaugural del 15-M logroñés. Entre las primeras acciones que se llevaron a cabo, destacó la aparición de un "tenderete protestón" donde cualquiera podía colocar unos cartones donde exponer sus quejas, sus problemas o sus ideas. Tuvo lugar además la primera asamblea, en cuya acta sus participantes se describían a sí mismos como "gente normal", personas "preocupadas por el panorama político, económico y social que vemos a nuestro alrededor. Por la corrupción de los políticos, empresarios, banqueros... Por la indefensión del ciudadano de a pie". Tratando de desmarcarse de una imagen excesivamente politizada, se presentaban como un "foro de protesta y debate", abierto a toda la ciudadanía sin exclusiones ideológicas.

La heterogeneidad de las propuestas refleja la diversidad de sensibilidades políticas que se hallaron presentes en aquel encuentro:

1. Derogación o cancelación de la reforma de pensiones y reforma laboral.

2. Reforma de la ley de las ETTs y contratos basura.

3. La transformación de las viviendas vacías en VPO.

4. Limitación y control del gasto en las campañas políticas.

5. Comisiones independientes que controlen y prevengan la corrupción.

6. Impuesto sobre los capitales especulativos: Tasa Tobin

7. Petición de revisión sobre el trabajo de la Fiscalía.

8. Expropiación de las fábricas abandonadas y creación de cooperativas de trabajadores en las mismas.

9. $\quad$ Solidaridad entre los pueblos y las personas.

10. Anulación inmediata de la ordenanza cívica de Logroño ${ }^{78}$.

Y por último, como petición más destacada, la modificación de la ley electoral para garantizar "un sistema auténticamente representativo y proporcional que

\footnotetext{
76 (2011) CALVO, Kerman, GÓMEZ-PASTRANA, Teresa y MENA, Luis, "Movimiento 15-M: ¿quiénes son y qué reivindican", Zoom político, $\mathrm{n}^{\circ} 4$, p. 6.

77 "El movimiento del 15M se traslada a la Plaza del Mercado". La Rioja, 19/5/2011.

${ }^{78}$ Que declara como sujetos de sanción administrativa distintos comportamientos en la vía pública de carácter político, como pegar un cartel o poner una mesa.
} 
no discrimine a ninguna fuerza política ni voluntad social, donde el voto en blanco y el voto nulo tengan también su representación"79.

La heterogeneidad de las propuestas evidenció que el consenso iba a ser muy difícil, cuando no imposible, pero había detrás de ellas el mismo hilo conductor. Como escribiría Alejandro Gómez, uno de los asistentes, en el periódico regional, no se trataba de preconizar ninguna revolución, sino de alentar "una reforma tan profunda del sistema que parece que es una revolución" ${ }^{80}$. Unas cuarenta personas pasaron la primera noche en la Plaza del Mercado, en tiendas de campaña. Al día siguiente una marcha recorrió diversas instituciones -donde sus representantes eran recibidos por los responsables- con panfletos y octavillas que informaban de los acuerdos adoptados ${ }^{81}$. La asamblea general, que fue masiva hasta el punto de obligar a dividir al público en grupos de veinte personas, adquirió un tono muy diferente a la anterior. En el acta desaparecen todas las menciones al foro de debate: el 15-M logroñés será a partir de entonces un movimiento, que además depurará todos los elementos que el día anterior presentaban un componente anticapitalista y disruptivo ${ }^{82}$.

Por otra parte, a partir de aquí comenzó a manifestarse una división entre los dos sectores de activismo que se haría más patente en los días siguientes: por un lado, el núcleo duro, que fue el más comprometido con el movimiento, y por otro, el de los asistentes, que acudían con regularidad a las asambleas pero sin implicarse ni en las comisiones ni en la acampada ${ }^{83}$. Se puede decir a grandes rasgos que el núcleo duro estaba compuesto por personas con militancia social y política, mientras que los asistentes se interesaron por el 15-M a través de lo que se difundía en medios de comunicación y redes sociales. Las diferencias se plasmaron en algunos problemas de convivencia que aparecieron en las acampadas, concretamente aquellos relacionados con la libertad de expresión, que mostraron graves carencias en la cultura cívica. Carlos Taibo cuenta que en Sol la presión consiguió retirar una pancarta que rezaba "la revolución será feminista o no será" ${ }^{4}$. En Logroño se vivió una escena similar cuando hubo que quitar otra que rezaba "hay vida más allá del capitalismo", después de una agria discusión en las redes sociales donde salió a relucir el argumento de que explicitar ciertas ideas políticas podía enajenar al movimiento el apoyo de la gente.

Para no ser excesivamente pesimistas, también se debe señalar que el 15-M mostró una capacidad de autogestión levantando un campamento en la Plaza del Mercado. A un costado fue instalada una carpa con un punto de información y mesas y paneles para el mismo fin, con materiales donados o prestados. El escenario portátil que había situado el Ayuntamiento para los actos electorales sujetaba pancartas y carteles. Al otro lado se situaron las tiendas de campaña ${ }^{85}$. Esta presencia permanente en un espacio público suscitó una dura controversia entre los principales partidos políticos riojanos, si

79 El acta está recogida en la fantástica página del 15-M logroñés: <http://www.xn-asamblealogroo-2nb.com/2011/05/19/acta-de-la-asamblea-1-18-5-11/>

80 "Por qué protesto". La Rioja, 19/5/2011.

81 (2011) CALVO, D. y MORGA, J., "El movimiento 15-M...", art. cit., p. 38.

82 < http://www.xn--asamblealogroo-2nb.com/2011/05/20/acta-de-la-asamblea-2-190511/> Lo cual no quita para que en los grupos de debate se deslizaran propuestas más radicales.

83 (2011) CALVO, K., GÓMEZ-PASTRANA, T. y MENA, L., "Movimiento 15-M...", art. cit., p. 9.

84 (2011) TAIBO, C., Nada será como antes..., op. cit., p. 35.

85 (2011) CALVO, D. y MORGA, J., "El movimiento 15-M...", art. cit., p. 38. 
bien todos coincidieron en mostrarse comprensivos con los participantes. Para el presidente autonómico, el conservador Pedro Sanz, aquellas se dirigían "contra quien gobierna España y contra el gobierno socialista". El PSOE, en cambio, instaba a los indignados a cambiar la política desde dentro. Por último las fuerzas minoritarias decían sentirse identificadas con el $15-\mathrm{M}^{86}$.

Estos discursos, junto con el hecho de que las voces más radicales se atenuaran como consecuencia de la amenaza de prohibir las acampadas en la jornada de reflexión electoral -ya no se podían gritar consignas a favor de la abstención-, contribuyeron a que la asamblea del día 20 congregara a unas mil doscientas personas ${ }^{87}$. Al día siguiente se crearon distintas comisiones: Expresión de Sentimientos y Emociones, Comunicación, Logística, Arte, Acción Directa No Violenta, Autocrítica e Y Ahora Qué ${ }^{88}$. El fin de alguna de ellas Expresión de Sentimientos y Emociones- responde a la importancia dada por el 15-M a los aspectos emocionales como el reforzamiento de la autoestima y de la afectividad positiva ${ }^{89}$.

Superado el reto de la jornada electoral, la asamblea logroñesa, siguiendo la decisión tomada en Sol, determinó que la acampada permaneciera en la Plaza del Mercado, por lo menos hasta el día 29 de junio. Pero esta decisión no impidió que los acampados fueran conscientes de que no iban a durar mucho tiempo en la plaza. Al miedo a un posible desalojo policial se unía por entonces el lógico cansancio que padecía el núcleo duro, después de varias jornadas de intensa actividad que habían forzado a pasar las asambleas de una periodicidad diaria a semanal. Se discutió también sobre la continuidad del movimiento, acordándose que había que dar un giro a la problemática local que partiría de una descentralización con respecto a las decisiones de la mediática Asamblea Sol, una decisión valiente pero controvertida. El 15-M logroñés elaboró entonces una hoja de ruta política dividida en temas nacionales y riojanos $^{90}$, aunque el estilo tan vago en el que estaba redactada no ayudó precisamente a su difusión.

Lo más importante de este documento era la decidida apuesta por la acción directa, la herramienta que había permitido ocupar la plaza, limitada en un principio a las protestas contra los EREs o las paralizaciones de desahucios ${ }^{91}$. Se pretendía sacar al 15-M de la Plaza del Mercado y comprometerle con las problemáticas sociales. El 27 de mayo tuvo lugar una manifestación espontánea en solidaridad con la acampada de Barcelona, en la que llegaron a participar más de un millar de personas y que se saldó sin ningún incidente. Dos días más tarde se desarrolló la conocida como Media Maratón de los Chorizos, una carrera de relevos simbólica que aprovechó la celebración de la

86 "El PP culpa a Zapatero del movimiento $15 \mathrm{M}$ y el PSOE apela al cambio desde las urnas". La Rioja, 20/5/2011.

87 (2011) CALVO, D. y MORGA, J., "El movimiento 15-M...", art. cit., p. 38

88 <http://www.xn--asamblealogroo-2nb.com/2011/05/22/acta-de-la-asamblea-4-21-5-2011/>

${ }^{89}$ (2013) PÁEZ, Darío, JAVALOY, Federico, WLODARCZYK, Anna, ESPELT, Esteve y RIMÉ, Bernard, "El movimiento 15-M: sus acciones como rituales, compartir social, creencias, valores y emociones", Revista de Psicología Social, n² 28, pp. 19-33.

90 "La hoja de ruta de la \#acampadalgño: primer borrador". La Rioja, 29/5/2011. Los temas riojanos tenían como línea directriz la «transformación ética y concienciación social». Lo más trascendente era la crítica a la ominosa ordenanza cívica recientemente aprobada por el Ayuntamiento.

${ }^{91}<$ http://www.xn--asamblealogroo-2nb.com/2011/05/23/acta-de-asamblea-5-22-5-11/> 
Media Maratón de Logroño, en la que corredores caracterizados como ciudadanos sufrían las zancadillas de otros disfrazados de políticos y banqueros $^{92}$.

La acción más emblemática se produciría el 11 de junio, coincidiendo el traspaso de poderes al nuevo equipo de gobierno municipal. Se trataba además del día de San Bernabé, fiesta patronal Logroño. Con anterioridad a esta conmemoración, ya habían tenido lugar densos debates en la plaza al saberse que el Ayuntamiento quería ubicar en ella una feria de artesanía. El problema de convivencia que se planteaba con la acampada fue resuelto manteniendo las tiendas de campaña, pero obligando a compartir el espacio con los artesanos ${ }^{93}$. Mientras tanto, se fue preparando discretamente la manera en la que el 15-M acudiría al acto de investidura, en línea con la propuesta que habían acordado portavoces de asambleas de todo el Estado en Sol ${ }^{94}$. El 8 de julio se hizo público que el 15-M logroñés realizaría una protesta hacia la toma de posesión mediante una concentración silenciosa y una cacerolada que acompañarían a la nueva corporación municipal durante la tradicional procesión de San Bernabé, que tiene precisamente como protagonista al regidor logroñés. No se dijo, sin embargo, que un pequeño grupo pensaba entrar en el Ayuntamiento y colarse en la ceremonia de gala para mostrar a los políticos locales las reivindicaciones del 15-M. Finalmente, una persona pudo entrar en la sala donde estaba teniendo lugar la ceremonia, lanzando una frase antológica: "mucho juráis y prometéis, pero no tenéis la decencia de sacar a los corruptos de las listas" ${ }^{\prime \prime}$. Posteriormente, miembros del 15-M recibieron a los concejales y a sus invitados al ágape que se había preparado en el ayuntamiento con panfletos y consignas.

A continuación, siguió la protesta en los cauces anunciados, participando varios centenares de indignados. El momento culminante fue cuando el Ayuntamiento, que se hallaba en la concatedral de la Redonda -anexa a la Plaza del Mercado- asistiendo al oficio religioso que precedía a la procesión, decidió quedarse en el edificio religioso más minutos de los necesarios mientras en el exterior se multiplicaban los ruidos de las cacerolas y de otros aparatos, así como los cánticos de protesta. En la procesión subsiguiente, los manifestantes tuvieron que soportar algunas agresiones e insultos por parte de personas que se encontraban dentro del público. Sin embargo, el balance general, realizado por la comisión de Acción Directa, fue positivo ante "la adhesión y el entusiasmo demostrado por los asistentes". Entendiendo que la protesta había causado molestias, Acción Directa recordaba que el malestar no conoce descansos ni fiestas, cuestionando al mismo tiempo la doble naturaleza político-religiosa del acto ${ }^{96}$. Todo lo cual no fue óbice para que la autocrítica se extendiera por el 15-M logroñés, como lo refleja la asamblea celebrada la misma tarde del día 11. Si bien el público reconoció que la manifestación no había sido violenta, acabó cuestionando tras varios debates la coincidencia

\footnotetext{
92 (2011) CALVO, D. y MORGA, J., "El movimiento 15-M...", art. cit., pp. 43-44.

93 "El campamento del 15M convivirá con el mercado renacentista en San Bernabé". La Rioja, 2/6/2011.

94 "El 15-M boicoteará las tomas de posesión de los alcaldes". El País, 5/6/2011.

95 (2011) CALVO, D. y MORGA, J., "El movimiento 15-M...", art. cit., p. 44.

$96<$ http://www.xn--asamblealogroo-2nb.com/2011/06/12/comunicado-de-la-comision-de-acciondirecta-de-acampada-logrono-sobre-las-acciones-realizadas-con-motivo-de-la-investidura-delayuntamiento-de-logrono/>
} 
entre la cacerolada y la procesión, así como censurando cierta desorganización ${ }^{97}$.

El episodio más trascendente para el 15-M logroñés desde la toma de la Plaza del Mercado terminó por tanto con un regusto amargo. Puede decirse que se había instalado cierto grado de miedo entre el núcleo organizador, sometido a presiones de todo tipo y que se sentía responsable de haberse enajenado el apoyo de la ciudadanía por esta acción. El tópico según el cual la sociedad logroñesa está ubicada en el conservadurismo político ${ }^{98}$, comenzó a calar muy hondo en la Plaza del Mercado, por más que las sospechas fueran infundadas. La manifestación del 19 de junio contra el Pacto del Euro congregó a más de cinco mil personas, siendo una de las más concurridas en los últimos años ${ }^{99}$. La prensa regional no dudó en calificarla como "toda una demostración de poder" ${ }^{100}$, demostrando con ello que los supuestos errores cometidos en la cacerolada del 11 de junio no habían erosionado la imagen popular del movimiento.

Por el contrario, el éxito de esta marcha puso también de relieve que el 15-M dependía en exceso de las mediáticas movilizaciones convocadas desde Sol. Las acciones directas y locales, como la protesta realizada el 7 de julio ante las oficinas del Servicio Riojano de Empleo y del INEM para invitar a los parados a sumarse al 15-M, no tenían tanta repercusión, por más que esta última en concreto contribuyera a denunciar con las humillantes colas que se formaban desde altas horas de la madrugada ${ }^{101}$. La división existente en el movimiento fue acentuándose con el paso de los días. El 22 de junio nació en La Rioja la plataforma ¡Democracia Real Ya!, sembrando de confusión el ambiente al no quedar clara su relación con el 15-M, circunstancia que se vio acentuada por el hecho de realizar su presentación en la Plaza del Mercado con las tiendas de campaña al fondo ${ }^{102}$. Más graves aún sin embargo fueron las diferencias internas con respecto al mantenimiento de la acampada. Siendo cada vez más insistentes los rumores sobre un inminente desalojo policial, el 7 de julio la asamblea decidió levantar la acampada en previsión de los incidentes violentos que se pudieran desencadenar con esta actuación. En cualquier caso, el comunicado de prensa advertía que "Asamblea Logroño tiene vocación de continuidad" y que pensaba extenderse al resto de la ciudad ${ }^{103}$. Parecía que se presentaba como avance lo que se trataba de un auténtico retroceso, pues ni siquiera se sabía dónde ofrecer algo tan básico como un lugar para reunirse. Tras casi dos meses ocupando pacíficamente la plaza, el 15-M se quedaba en la calle.

Durante los meses de verano, entre el calor, la celebración de las marchas indignadas y la organización de asambleas en los pueblos riojanos, la falta de un punto de referencia no fue un escollo insalvable para el movimiento, e incluso la Plaza del Mercado seguiría acogiendo asambleas y otras actividades. Los problemas comenzaron con la llegada del otoño y el cambio estacional. Por

\footnotetext{
$97<$ http://www.xn--asamblealogroo-2nb.com/2011/06/12/acta-de-asamblea-18-11-6-11/>

${ }^{98}$ (2011) CALVO, D. y MORGA, J., "El movimiento 15-M...", art. cit., pp. 44-45.

99 Ibídem.

100 "El 15M exhibe su fuerza con una marcha multitudinaria". La Rioja, 20/6/2011.

101 (2011) CALVO, D. y MORGA, J., "El movimiento 15-M...", art. cit., pp. 45-46.

102 "Nace Democracia Real Ya en La Rioja". La Rioja, 23/6/2011.

103 <http://www.xn--asamblealogroo-2nb.com/2011/07/08/comunicado-de-desalojo-de-la-plaza/>
} 
otra parte, las actas de las asambleas testimonian un desánimo cada vez mayor entre los participantes. El 31 de agosto, en un micrófono abierto donde se daban opiniones con respecto a la reforma constitucional para incluir un techo al déficit presupuestario, alguien afirmaba que "hay [una] resignación permanente y completa. No se ve viable el cambio y la crisis fuera de esta plaza se ve como algo que no se puede cambiar"104. Mientras que dos los grandes partidos eran capaces de consensuar con carácter de urgencia una medida discutible, el 15-M no podía fijar un posicionamiento unánime, ni siquiera en asambleas de tamaño reducido como la logroñesa. El 28 de septiembre, cuando había que acordar la posición del movimiento con respecto a la huelga general de los sindicatos minoritarios, un sector bloqueó todo apoyo al paro con el argumento más bien peregrino de "no tenemos por qué definirnos respecto a un tema cuando nos lo piden"105.

En este contexto de reflujo la manifestación del 15 de octubre significó un nuevo repunte de participación, con una asistencia en torno a las seis mil personas y la imagen del regreso de las tiendas de campaña a la Plaza del Mercado $^{106}$, pero finalmente no serviría como revulsivo. El 15-M logroñés no consiguió consensuar ninguna decisión con respecto a las elecciones del 20 de noviembre ni la estrategia a seguir: si bien había unanimidad en no pedir apoyo al bipartidismo y "dinamitar" su mayoría absoluta, surgieron varias discrepancias sobre qué opción de voto proponer públicamente. Algunas voces abogaron porque el 15-M se pronunciara a favor de los partidos minoritarios, aduciendo que tanto el voto nulo como la abstención beneficiaban a las fuerzas mayoritarias, lo que a su vez implicaba participar en el juego electoral. Finalmente, la asamblea adoptó como acuerdo final el de no posicionarse a favor de ningún partido ${ }^{107}$. Esto supuso abandonar de manera definitiva una de las señas de identidad del $15-\mathrm{M}$, representada por el lema "No nos representan", sustituido ahora por la neutralidad electoral.

\section{Conclusiones}

Como hemos visto, en esta primera etapa, que abarca del 15 de mayo al 20 de noviembre de 2011, el movimiento 15-M cosechó un gran impacto que se asentaba en una divergencia cultural previa, la nula capacidad de respuesta por parte de los políticos y el uso de las nuevas tecnologías de comunicación. Pero sin embargo no pudo capitalizar este éxito y conseguir que las élites aceptaran unas reivindicaciones que la ciudadanía asumía mayoritariamente como propias. En esta lógica, más que de un fracaso del 15-M, habría que hablar de una derrota de la incipiente sociedad cívica, pese a que el movimiento demostraría finalmente que no podía ofrecer una alternativa ni constituirse en contrapoder. Pero no todo fueron decepciones. El sociólogo Manuel Castells señalaba al año siguiente que las brasas del 15-M seguían vivas gracias a las asambleas de barrio y las redes de solidaridad, que permitieron que prosiguieran funcionando algunas comisiones y que el respaldo

\footnotetext{
104 <http://www.xn--asamblealogroo-2nb.com/2011/08/31/acta-33-asamblea-extraordinaria-28de-agosto-de-2011/>

$105<$ http://www.xn--asamblealogroo-2nb.com/2011/11/09/acta-38-asamblea-general-28-9-11/>

106 "El hartazgo vuelve a tomar las calles". La Rioja, 16/10/2011.

$107<$ http://www.xn--asamblealogroo-2nb.com/2011/11/09/acta-46-asamblea-general-2-11-11/>
} 
popular continuara siendo considerable, tal y como lo ponían de manifiesto algunas acciones concretas ${ }^{108}$, como el movimiento antidesahucios, las mareas cívicas, las protestas vecinales, etc. Incluso cabe valorar su trascendencia como caldo de cultivo donde han aparecido nuevas formaciones políticas, como Podemos.

Son variadas y heterogéneas las razones que explican el abrupto fin de la tendencia al alza del 15-M, pero en estas conclusiones nos centraremos en las internas. Al parecer ha habido varios problemas con los auténticos órganos sobreranos del movimiento las asambleas. Aunque el método deliberativo forma parte del ADN de los movimientos sociales como elemento discursivo y organizativo, no es lo mismo ejercer la democracia directa y participativa en recintos de acceso más o menos limitado -campamentos, foros sociales, centros autogestionados $u$ otras esferas militantes reducidas- que en un espacio público y abierto. Ya fuese por imposibilidad o inexperiencia, las asambleas no lograron elaborar un programa político coherente, pues ya resultaba enormemente complejo jerarquizar temas, escenificando por el contrario diversos conflictos, principalmente relacionados con la ambigua identidad del movimiento, como se ve en las disputas en torno a la participación en la huelga general del 29 de septiembre ${ }^{109}$.

El discurso del 15-M se encuentra más enfocado al humanismo que al materialismo, lo que distorsiona su alcance político. El contexto conflictivo en que surge el movimiento activa además la necesidad de sus miembros de identificarse socialmente, un fenómeno que se traduce en una percepción de similitud entre ellos, una identificación con unos valores y creencias colectivos, el aumento de los sentimientos positivos -atracción y empatía- y la estimulación de las relaciones internas de cooperación y solidaridad. En este plano, y siguiendo a Émile Durkheim, los rituales colectivos, como las manifestaciones y las reivindicaciones, desempeñan un importante papel al reafirmar la solidaridad y los valores del grupo y reforzar la comunidad emocional $^{110}$. Sobre el individuo recae el protagonismo frente al grupo, lo que lleva a privilegiar el consenso como forma de acuerdo: es más importante que todos estén de acuerdo con una decisión, a que esta salga adelante aprobada por un parte, dividiendo fatalmente al movimiento. La búsqueda permanente del consenso implica aspectos positivos como el aprendizaje, pero también el inmovilismo, porque se prefiere no llegar a acuerdos que pasar a un sistema de votaciones $^{111}$. La consecuencia más negativa fue que en ocasiones no se adoptaron medidas de calados por miedo a imponer a toda la asamblea una decisión.

Algunos expertos citan a Theodor W. Adorno para invocar el fantasma de la pseudomovilización, la realización de un conjunto de protestas ilusorias y

\footnotetext{
${ }^{108}$ CASTELLS, Manuel, “¿A dónde van los indignados?”. La Vanguardia, 21/1/2012.

109 (2012) NEZ, Heloïse, "Entre los militantes y los laboratorios deliberativos: el 15-M", en TEJERINA, Benjamín y PERUGORRIA, Ignacio (eds.), From social to political. New forms of mobilization and democratization. Conference proceedings, Servicio Editorial de la Universidad del País Vasco, Bilbao, pp. 123-138.

${ }^{110}$ (2013) PÁEZ, D., JAVALOY, F., WLODARCZYK, A., ESPELT, E. y RIMÉ, B., "El movimiento 15-M...", art. cit., pp. 19-33.

111 (2012) NEZ, H., "Entre los militantes...", op. cit., p. 130.
} 
aparentes que acaban en nada porque sus protagonistas entienden que será muy difícil cambiar lo que pretenden ${ }^{112}$, el cual, junto con el "fetichismo cibernético"113, constituye el principal problema de los movimientos sociales actuales. No por eso, en cualquier caso, las protestas han menguado, sino que se han canalizado a través de otros ámbitos.

\section{Bibliografía}

(1996) AGUILAR, Paloma, Memoria y olvido de la Guerra Civil española, Alianza, Madrid, 1996.

(2006) BOBBIO, Norberto, Estado, gobierno y sociedad. Por una teoría general de la política, ed. Fondo de Cultura Económica, México D. F.

(2011) BOTELLA-ORDINAS, Eva, "La democracia directa de la Puerta de Sol". La vie des idées. 24/5/2011. <http://www.booksandideas.net/La-democraciadirecta-de-la-Puerta.html>

(2011) CALVO, David y MORGA, Jairo, "El movimiento 15-M en Logroño. La democracia en la plaza", Piedra de rayo, n³ 38 , pp. 32-48.

(2011) CALVO, Kerman, GÓMEZ-PASTRANA, Teresa y MENA, Luis, "Movimiento 15-M: ¿quiénes son y qué reivindican", Zoom político, no 4, pp. 417.

(2012) CAMPADABAL, Pep, "CT y política: la lucha por el punto medio. Del "pacto con el régimen, de entrada, no" a la victoria de la CT", en MARTíNEZ, Guillem. CT o la Cultura de la Transición. Crítica a 35 años de cultura española, Ed. Debolsillo, Barcelona, pp. 65-76.

(2005) CARBÓ, Rosa, PRADEL, Marc, DUARTE, María Luisa y HERREROS, Tomás, "La última oleada de movilizaciones (2002-2004)", en IBARRA, Pedro y GRAU, Elena (coords.), La política en la red: anuario de movimientos sociales, Ed. Icaria, Barcelona, pp. 34-52.

(2011) CASQUETE, Jesús, "Balance preliminar de la indignación", El Viejo Topo, n² 286, pp. 19-25.

(2012) CASTAÑOS, Guiomar, “El 15-M en Barcelona”, Ekintza Zuzena, nº 39.

(2014) CLAVERO, Bartolomé, España, 1978: la amnesia constituyente, Ed. Marcial Pons, Madrid.

(2012) COLECTIVO CUL DE SAC: 15-M. Obedecer bajo la forma de rebelión, Ediciones de El Salmón, Madrid.

(1995) DEBORD, Guy, La sociedad del espectáculo, Ediciones Naufragio, Santiago de Chile.

(2011) DIRECCIÓN GENERAL DE POLÍTICA INTERIOR: "El voto en blanco y el voto nulo en las elecciones locales del 22 de mayo de 2011", Seguridad y Ciudadanía. Revista del Ministerio del Interior, nº 6, pp. 303-312.

112 (2013) OÑATE, P., "La movilización...", art. cit., pp. 49-50.

113 (2013) RENDUELES, César, Sociofobia. El cambio político en la era digital, Capitán Swing, Madrid. 
(2011) ERREJÓN, Íñigo, "El 15-M como discurso contrahegemónico", Encrucijadas. Revista de Ciencias Sociales, no 2, pp. 120-145.

(2009) FERNÁNDEZ SARASOLA, Ignacio, Los partidos políticos en el pensamiento español. De la Ilustración a nuestros días, Ed. Marcial Pons, Madrid

(2012) FERNÁNDEZ-SAVATER, Amador, "Emborronar la CT (del "No a la guerra" al 15-M)", en MARTíNEZ, Guillem, CT o la Cultura de la Transición. Crítica a 35 años de cultura española, Ed. Debolsillo, Barcelona, pp. 37-52.

(2004) FISHMAN, Robert, "Legacies of democratizing reform and revolution: Portugal and Spain compared". Paper presentado en un seminario del Instituto de Ciências Sociais de la Universidade de Lisboa, 27/4/2004.

(2009) GONZÁLEZ, Juan Jesús y BOUZA, Fermín: Las razones del voto en la España democrática, 1977-2008, Ed. Los Libros de la Catarata, Madrid.

(2011) JIMÉNEZ SÁNCHEZ, Manuel, La normalización de la protesta. El caso de las manifestaciones en España (1980-2008), Centro de Investigaciones Sociológicas, Madrid.

(2007) KAASE, Max, "Perspectives on political participation", en DALTON, Russell J. y KLINGEMANN, Hans-Dieter (eds.), The Oxford Handbook of political behavior, Oxford University Press, Oxford-Nueva York, pp. 788-793.

(2012) MARCO de PABLO, Laia, "Sobre las dificultades para la eficacia comunicativa de los Movimientos Sociales. Repensar y actuar", Fòrum de recerca, $\mathrm{n}^{\circ}$ 17, pp. 91-107.

(2012) MARTíNEZ, Guillem, "El concepto CT", en MARTíNEZ, Guillem. CT o la Cultura de la Transición. Crítica a 35 años de cultura española, Ed. Debolsillo, Barcelona, pp. 13-24.

(2013) MUÑOZ MOLINA, Antonio, Todo lo que era sólido, Ed. Seix Barral, Barcelona.

(2007) MUÑOZ SORO, Javier, "Sin complejos: las nuevas derechas políticas españolas", Historia y política, no 18, pp. 129-164.

(2006) NAVARRO, Vicenç, El subdesarrollo social de España: causas y consecuencias, Ed. Anagrama, Barcelona.

(2012) NEZ, Heloïse, "Entre los militantes y los laboratorios deliberativos: el 15M", en TEJERINA, Benjamín y PERUGORRIA, Ignacio (eds.), From social to political. New forms of mobilization and democratization. Conference proceedings, Servicio Editorial de la Universidad del País Vasco, Bilbao, pp. 123-138

(2000) NOGUERA, José Antonio, "La restauración de la política social en España: conclusiones", en ADELANTADO, José (coord.), Cambios en el Estado del Bienestar: políticas sociales y desigualdades en España, Ed. Icaria, Barcelona, pp. 475-502.

(1998) OÑATE, Pablo, Consenso e ideología en la transición política española, Centro de Estudios Políticos y Constitucionales, Madrid. 
_ (2013) "La movilización ciudadana en España en los albores del siglo XXI: una contextualización para el debate", Revista española de ciencia política, $\mathrm{n}^{\circ}$ 33, pp. 31-55.

(2012) ORTIZ HERAS, Manuel, "Nuevos y viejos discursos de la Transición: la nostalgia del consenso", Historia Contemporánea, nº 44, pp. 337-367.

(2013) PÁEZ, Darío, JAVALOY, Federico, WLODARCZYK, Anna, ESPELT, Esteve y RIMÉ, Bernard, "El movimiento 15-M: sus acciones como rituales, compartir social, creencias, valores y emociones", Revista de Psicología Social, $\mathrm{n}^{\circ} 28$, pp. 19-33.

(2012) PEÑA ACUÑA, Beatriz, "Algunas perspectivas socioculturales de las redes sociales", en DE HARO, María Verónica, GRANDíO, María del Mar y HERNÁNDEZ, Manuel, Historias en red: impacto de las redes sociales en los procesos de comunicación, Universidad de Murcia, Murcia, pp. 299-329.

(2013) PÉREZ VICENTE, Nuria, "El lenguaje político del 15-M: hacia una nueva retórica de la indignación", Signa: revista de la Asociación Española de Semiótica, n² 22, pp. 569-594.

(2014) QUAGGIO, Giulia, La cultura en transición, Ed. Alianza Editorial, Madrid. (2009), SAMPEDRO, Víctor, "Conspiración y pseudocracia. O la esfera pública a cinco años del colapso del 11-M", Viento sur. Por una izquierda alternativa, $\mathrm{n}^{\circ}$ 103, pp. 60-68.

_ (2011) y SÁNCHEZ DUARTE, José Manuel, "Del 13-M al 15-M", Razón y fe: revista hispanoamericana de cultura, n 1353-1354, t. 264, pp. 99-105.

_ (2006) y LÓPEZ-REY, José Antonio, "Nunca máis y la cara oculta de la esfera pública: control de la visibilidad mediática de un movimiento social", en NOS, Eloísa y GÁMEZ, María José (eds.), Medios de comunicación y solidaridad: reflexiones en torno a la (des)articulación social, Universitat Jaume I, Castellón, pp. 88-103.

(2005) SARASQUETA, Antxon, "El proyecto de la izquierda española", Cuadernos de pensamiento político, $\mathrm{n}^{\circ}$ 5, pp. 147-166.

(2011) TAIBO, Carlos, Nada será como antes: sobre el movimiento 15-M, Ed. Los Libros de la Catarata, Madrid.

_ (2011) El 15-M en sesenta preguntas, Ed. Los Libros de la Catarata, Madrid

(2011) VALLESPÍN, Fernando, "La fatiga democrática", Claves de razón práctica, n² 215, pp. 10-18.

(2005) YSÀS, Pere, "Una nota sobre la crisi del franquisme i la transició a la democracia", Revista HMiC: història moderna i contemporània, no 3,, pp. 101109. 